\title{
The Impact of Perceived Organizational Support on the Quality of Educational Services at Arab Universities
}

\author{
Dr. Muhammad Falah Ali Al-Khawaldeh ${ }^{1} \&$ Dr. Khalid bin Madhi Muhammad Hakami ${ }^{2}$ \\ ${ }^{1}$ Associate Professor, Department of Curriculum and Instruction, The World Islamic Science \& Education \\ University, The Hashemite Kingdom of Jordan \\ ${ }^{2}$ Educational Supervisor at the General Administration of Education, Jizan / Kingdom of Saudi Arabia \\ Correspondence: Dr. Muhammad Falah Ali Al-Khawaldeh, Associate Professor, Department of Curriculum and \\ Instruction, International Islamic Science University, The Hashemite Kingdom of Jordan
}

Received: January 5, 2020

Accepted: January 27, 2020

Online Published: January 29, 2020

doi:10.5539/mas.v14n2p57

URL: https://doi.org/10.5539/mas.v14n2p57

\begin{abstract}
The current study explored the impact of perceived organizational support-on the quality of educational services at Arab universities. The descriptive analytical approach was used with a total sample consisting of 215 participants, from Jizan University, and participants from the International Islamic Sciences University. The results of the study showed that the level of both the perceived organizational support and the quality of educational services in universities, the study sample was medium. The results also showed a significant impact of the perceived organizational support on the quality of educational services at Arab universities. In addition to that, there are significant differences at the level of $(\alpha \leq 0,05)$ in the quality of educational services level (quality of academic and administrative services, and the quality of facilities and equipment and quality of reputation) at Arab universities that can be attributed to (gender). And no significant differences at the level of $(\alpha \leq 0,05)$ in the quality of educational services level (Quality of academic services, quality of administrative services, quality of facilities and equipment and quality of reputation) at Arab universities, that can be attributed (to experience and work nature). The study recommended the necessity of raising the level of perceived organizational support and raising the quality of educational services at Arab universities.
\end{abstract}

Keywords: perceived organizational support, quality of educational services

\section{Introduction}

University education is the focus of attention of all countries, due to the great role that university education plays in preparing and making future generations, the main drive for economic and social sectors (Sady et al., 2019). In light of the increased competition in the educational sector in the Arab countries and the shortage of job opportunities faced by university graduates, these universities should, Arab universities should re-double their efforts to build an educated person capable of actively taking part in achieving the development programs that help such countries compete at the local, regional, and global levels (Issa \& Siddiek, 2012). Recent years have witnessed a number of challenges that have been highlighted by behavioral studies (Jayasree \& Sheela, 2012), the most prominent of which is the perceived organizational support. Perceived organizational support is a modern management concepts in the management literature, and a necessity for any organization's success in providing a quality service commensurate with societal needs, and for facing internal and external challenges.

Given the increasing pressure on governments by students, parents, and the labor market to improve universities for their educational programs, care must be taken to improve the quality of education (Al-Haddad et al., 2018). In this context, the processes to improve the quality of higher education require universities to pay attention to internal processes, including perceived organizational support, which refer to employee's perception concerning the extent to which the organization values their contribution and also cares about their general well-being (Jayasree \& Shella, 2012).

The concept of perceived organizational support stems from the theory of Social Exchange (Blau, 1964; Eisenberger et al., 1997) and Benefits Exchange (Allen et al., 2003). These theories have contributed to explaining the underlying motivation behind trends, and mutual behaviors between individuals and groups. Eisenberger et al. (1997) had the greatest role in the application of these two theories in order illustrate and 
explain the relationship between the organization and its employees, as they build general perceptions of the organization's intentions and attitudes towards them. Perceived Organizational Support includes organizational justice, which refers to the way in which employees judge the fairness of the method used by the manager in dealing with the professional and humanitarian levels (Abdel-Salam, 2005). In addition to leaders' behaviors to support subordinates (Shahly, 2016). And participation in decision making (Al-Rifai, 2009). Finally, it also includes self-esteem of employees (Shahly, 2016). The quality of the educational service includes both academic aspects, administrative aspects, facilities and equipment, and Reputation (Al-Tuwaijri \& Abdullah, 2016).

Based on the support provided by the university, employees' responses to their positive support is to exert more effort to improve performance at work. Therefore, the study came to identify the impact of perceived organizational support in Arab universities on the quality of educational services from the point of view of workers, as well as knowing the level of quality of educational services provided, and trying to improve them.

\section{Terminology}

\subsection{Perceived Organizational Support}

Dawley, et al. (2008, p. 240) defined 'perceived organizational support' as "The degree to which employees form impressions that their superiors care about their well-being, value their efforts and contributions, takes care of him and are generally supportive. Employees tends to appreciate the efforts and rewards provided by the organization, being considered as the organization appreciates the employees' contribution, and is concerned with their well-being.

\subsection{Quality of Educational Services}

'Quality of educational services' is defined as "The success of the educational organization in providing an appropriate educational environment that enables students to effectively achieve educational goals in accordance with appropriate academic standards" (Al-Hadabi, 2006, p. 14).

\subsection{Quality of Educational Services}

'Quality of educational services' is defined as "The success of the educational organization in providing an appropriate educational environment that enables students to effectively achieve educational goals in accordance with appropriate academic standards" (Al-Hadabi, 2006, p. 14).

\section{Literature Review}

\subsection{First: Previous Studies Related Perceived Organizational Support}

Al-AEnezi\& Al-Qarni (2018) conducted a study aimed at identifying the level of POSat secondary schools in Hafr Al-Batin from the point of view of teachers. The researcher used the relational descriptive approach, and the questionnaire as a data collection tool. The study sample consisted of (407) male and female secondary school teachers in Hafr Al-Batin. The most important results was that the level of organizational support at the secondary schools of Hafr Al-Batinwas of a high degree of perception. The study also showed that there is a significant positive, high-value correlation relationship between the degree of perceived organizational support atthe secondary schools ofHafr Al-Batin, and the level of organizational citizenship behavior among male and female teachers.

Al-Ani (2018) carried out a study that aimed at diagnosing the POS level, and its compatibility with the nature of the prevailing organizational culture pattern at the University of Mosul. The researcher used the questionnaire to collect data, and the study sample was 134 . The researcher used the descriptive analytical approach. The study concluded that there is consensus between POS and the organizational culture in the research field. There were also significant differences between organizational justice and the prevailing organizational culture pattern (role culture). The researcher recommended the need to pay attention to the human resources working at the university.

Al-Ka'abi (2017) conducted a study that aimed at identifying the nature of the relationship between POS, and the organizational cynicism of the opinions of a faculty sample at Al-Rafidain University College. The sample included (57) faculty members. The researcher used the descriptive approach and a questionnaire for data collection. The results indicated that there is a correlation, and a negative impact between the study variables. The study recommended the college to pay attention to the special conditions of the faculty members, and to provide all the capabilities that help them perform well.

Shahli (2016) carried out a study aimed at revealing the relationship between organizational support and job stability at Mohamed Boudiaf University. The study sample consisted of (500) employees. The adopted the descriptive approach, and the researcher used two tools to collect information, namely observation and 
questionnaire. The study concluded that the relationship between organizational support and job stability is causal, and so if workers feel an interest in their work, they will settle in it. Therefore, the application of organizational justice contributes to motivating workers, raising their occupational level, and achieving their job satisfaction.

Dawley, et al., (2008), carried out a study that aimed at examining the impact of supervisory support and POS on organizational commitment, and job behavior of the study, the study consisted of (346) employee at the American manufacturing sites. The study concluded that the perceived organizational support, whether in the branches, or the parent companies, has shown a significant relationship with organizational commitment.

Al-Adayleh (2007) conducted a study that aimed at identifying the nature of POS that Jordanian universities provide to faculty members, and its impact on their loyalty towards the university, and identifying the organizational loyalty dimensions that are mostly influenced by POS, and whether there are differences in POS, and organizational loyalty between state and private universities. The researcher used a questionnaire to collect information from a sample of (213) faculty member. The study concluded that the POS level provided by the Jordanian universities was at a medium degree, there is also a strong correlative direct correlation between its three dimensions, and there is also a significant correlational relationship at positive levels between POS level and the level of organizational loyalty. The study recommended that Jordanian universities should provide the necessary services needed by faculty members, improve their working conditions, and develop a system of incentives that enhance their bounty.

\subsection{Second: Previous Studies Related to the Quality of Educational Services, Presented from Newest to Oldest as Follows}

Zaqai and Wazzani (2017) conducted a study that aimed at identifying the impact of the quality of educational services provided by Sa'eedah University in Algeria on student satisfaction. The study used the descriptive analytical approach. The study sample consisted of (370) students. A questionnaire was used to collect data, and the study showed that the degree of students' appreciation of the dimensions of the quality of educational services provided at the university was medium. The results also showed that the level of students' satisfaction with the quality of educational services at the university at a medium degree, with a significant effect of the educational service quality on the satisfaction of the university students under study. The study recommended the necessity of paying attention to modern methods of dealing with students, listening to their voice, and focusing on them because they are the focus of all educational processes.

Al-Tuwaijri and Al-Ajami (2016) presented a study that aimed at developing a scale to measure the quality of educational services provided to students, and it was applied to a sample of (119) students, of the departments of mathematics and physics at the Faculty of Science at Imam Muhammad bin Saud Islamic University. The study used the descriptive survey approach, and the results revealed that the majority of the study sample satisfaction degree with the educational services in the college was medium.

Al-Shanti (2015), carried out a study that aimed at assessing the level of educational service quality in the College of Administrative Sciences at the University of Najran, Saudi Arabia. The researcher used the descriptive and inferential approach. The sample consisted of (104) male and female students based on the academic level, gender, and college environment. A questionnaire was used to collect data was collected by questionnaire. The results revealed that the level of educational service quality in the college is medium, and that there are significant differences between students 'responses to the level of educational service quality due to research variables. The study recommended that more research be conducted in the field of educational services quality at all colleges according to the research axes, in addition to other axes.

Saif et al. (2014) conducted a study that aimed at assessing the quality of student services and student satisfaction in Jordanian public universities. The researchers used the questionnaire as a tool to collect information, and found that the students' evaluation of the quality of all services (student / academic / non-academic) came at a medium degree. The study showed that there were significant differences due to the gender variable.

The goal of Salman Study (2013) was to measure the quality of university services at Al-Aqsa University. The scale consisted of six dimensions, and the sample consisted of (380) male and female students, The researcher used the descriptive approach, and the study revealed that the quality of university services was between weak and medium in most dimensions of the scale, and that there were statistically significant differences attributed to the gender variable, in favor of females. The study recommended the need to promote the level of university services in the scale's dimensions as a whole. 
The study of Douglas et al. (2006) used the SERVQUAL scale to identify the level of student satisfaction with the quality of educational services provided at the University of Bari, Italy. The study used the interview as a tool to collect information, and the revealed that students are less satisfied with the quality of educational services provided by the university, and that the size and quality of educational services do not rise to the level of competition.

In light of what has been previously presented from previous studies, which the researcher was able to view, it becomes clear that POS variable and its impact on the quality of educational services at the Arab universities were not covered locally and regionally, and that it still badly needs more research and investigation.

\section{Study Aims}

This study aims mainly to identify the impact of perceived organizational support on the quality of educational services at Arab universities from the point of view of academic and administrative workers.

More specifically, the study aims to answer the following questions:

1. What is the Perceived Organizational Support-level at Arab universities from the point of view of the study subjects?

2. What is the Quality of Educational Services level at Arab universities from the point of view of the study subjects?

3. Is there a significant impact at the level of $(\alpha \leq 0,05)$ of the Perceived Organizational Support dimensions (organizational justice, leaders' behavior to support subordinates, participation in decision-making, and self-esteem of workers) on the Quality of Educational Services at the Arab universities under study?

4. Are there statistically significant differences at the level of $(\alpha \leq 0,05)$ in the Quality of Educational Services level at Arab universities that can be attributed to demographic variables (gender, work nature and years of experience)?

\subsection{Study Importance}

This the first study in its subject that explores the impact of perceived organizational support on the quality of educational services at Arab universities. The study derives its importance from the necessity of achieving a deeper understanding of perceived organizational support, and showing the impact of the dimensions, and standards of perceived organizational support (organizational justice, leaders' behaviors to support subordinates, participation in decision-making, self-esteem of workers) that are the most influential on the quality of educational services. This provides university presidents and university administrations with more rationalization of their behaviors and decisions.

On the other hand, Insufficient research writings in the field of perceived organizational support, and the quality of educational services, and therefore this study comes as a complement and as an extension to other studies carried out in this field. In addition, this study displays the opinions of the participants in their educational institutions, which can be used to provide information that helps in developing and improving the services provided to students.

\section{Method and Procedures}

\subsection{Approach}

This study is designed to determine the impact of perceived organizational support on the quality of educational services at Arab universities. The study follows sequential procedures as a strategy for the mixed methods that have been applied. The researcher collects qualitative data that are quantitatively analyzed.

\subsection{Population}

The study population consisted of 403 employees at Jizan University in the Kingdom of Saudi Arabia, and 203 employees at the World University of Islamic Sciences in Jordan, in the academic year 2019, according to the statistics of the Ministry of Education in the Kingdom of Saudi Arabia, and the Jordanian Ministry of Education.

\subsection{Sample}

The sample of the study consisted of about 234 participants randomly selected employees from the study population. The sample size was determined based on the Krejcie\& Morgan Sample Selection Table (Krejcie\& Morgan, 1970, pp. 607-610), At the level (0.05) of significance, with 134 questionnaires being distributed at Jizan University in the Kingdom of Saudi Arabia, and 100 questionnaires at the International Islamic Sciences 
University in the Hashemite Kingdom of Jordan, at their workplaces. After receiving the questionnaires back, 12 questionnaires from Jizan University were, and 7 questionnaires the International Islamic Sciences University were excluded for incomplete with a total of 215 participants 122 participants from Jizan University, and 93 participants from the International Islamic Science University. Table 1 shows the distribution of the study subjects according to the demographic variables:

Table 1. Distribution of Study Subjects According to Categorical Variables

\begin{tabular}{cccc}
\hline Variable & Level & Number & Percentage \\
\hline \multirow{2}{*}{ University } & Jizan University & 122 & 56.7 \\
& The World Islamic Sciences \& & 93 & 43.3 \\
Education University & Male & 143 & 66.5 \\
Gender & Female & 72 & 33.5 \\
& Less than 5 years & 92 & 42.8 \\
Experience & 5-10 years & 98 & 45.6 \\
& More than 10 years & 25 & 11.6 \\
\multirow{3}{*}{ Work Nature } & Academic & 150 & 69.8 \\
& Administration & 65 & 30.2 \\
& Total & 215 & 100.0 \\
\hline
\end{tabular}

\subsection{Study Tool}

To achieve the study objectives, a questionnaire was designed and codified after review of the theoretical framework and literature where information related to perceived organizational support and quality of educational services were collected. The questionnaire was influenced by significant research in the area (Al-Enizi \& Al-Qarni (2018), Al-Ka'abi (2017), Al-Adayleh (2007), and Shahla (2016)). In terms of the perceived organizational support dimensions (the independent variable), and on the study of Al-Tuwaijri and Al-Ajami (2016) in terms of quality of educational services dimensions (dependent variable). The final questionnaire consisted of demographic characteristics of the study subjects including (gender, work nature, years of experience). And 25 for perceived organizational support in its dimensions: Organizational Justice: (1-8) items, Leaders' behavior to support subordinates: (9-14) items, Self -esteem of workers (15-20) items and Participation in decision-making: (21-25) items. And (61) for quality of educational services in its dimensions: Academic aspects: 17 items, Administrative aspects: 17 items, Facilities and equipment: 21 items, and Reputation: 6 items.

A Likert Scale where grades 1, 2, 3, 4, 5 were awarded to totally agree, agree, neutral, disagree, absolutely disagree. The mean values concluded by the study were dealt with as follows and in accordance with the following formula:

High value - the minimum value of the answer alternatives divided by the number of levels, that is:

$$
\frac{5-1}{3}=\frac{4}{3}=1.33 \text { This value is equal to the length of the class. }
$$

Thus, the low level is from $1.00+1.33=2.33$

The mean level is from $2.34+1.33=3.67$

The high level is from 3.68-5.00

\subsection{Tool Validity (Content Validity)}

The content validity of the study tool was verified after presenting it to a number of reviewers specialized in the field of educational administration and evaluation and assessment at each of Jizan University, in Saudi Arabia, and the International University of Islamic Sciences in Jordan. To express their opinions and suggestions in terms of the tool's clarity, wording accuracy of the tool's paragraphs, and the extent to which they express of the tool content, its link to the study objectives, the adequacy of the paragraphs of each axis, and the tool as a whole. The reviewers modified the study tool, either by deleting some of its paragraphs, modifying them, or adding 
what is necessary. The reviewers' agreement $(90 \%)$ on the validity of the paragraph is a criterion for approving it.

\subsection{Tool Reliability}

The study instrument reliability was verified by applying Cronbach's alpha, where the values of the Cronbach alpha coefficient were acceptable for the purposes of the current study. The values of the Cronbach alpha coefficient for the sub-dimensions of the scale were higher than 0.60 , which are acceptable values for the purposes of the current study.

\subsection{Data Collection}

The sources of data for the study are classified into primary and secondary data. The primary data are the results of the questionnaire. The secondary data include books, previous studies, academic journals, etc., to formulate hypotheses and determine the theoretical framework of the study.

\subsection{Statistical Processing}

Statistical methods were used by using the Statistical Packages for Social Sciences (SPSS).

\section{Results}

In this part of the study, the study questions will be answered to identify the study results related to the impact of perceived organizational support on the quality of educational services in Arab universities, and the following are the results. The results are as follows:

\section{What is the perceived organizational support level at Arab universities from the point of view of the study subjects?}

The result shows that the means and standard deviations of the perceived organizational support level at Arab universities from the point of view of the study subjects:

The means for (perceived organizational support) at Arab universities ranged between 3.19 and 3.07, where the perceived organizational support in general received a total mean of 3.11, which is a medium level. Self-esteem of workers came first, with the highest mean of 3.19 and a standard deviation of 0.85 which is a medium level. Leaders' behavior to support subordinates came second, with a mean of 3.10 and a standard deviation of 0.79 , which is a medium level. Organizational justice, and participation in decision-making came third with a mean of 3.07 and a standard deviation of 0.79 and 0.90 , respectively, which is a medium level.

\section{What is the quality of educational services level at Arab universities from the point of view of the study subjects?}

The result shows that the means for (quality of educational services) at Arab universities ranged between 3.36 and 3.06, where the educational services in general got a total mean of 3.25, which is a medium level. Quality of Administrative services came first, with the highest mean of 3.36 and a standard deviation of 0.53 which is a medium level. Quality of facilities and equipment came second, with a mean of 3.31 and a standard deviation of 0.45 , which is a medium level. Reputation quality came third with a mean of 3.28 and a standard deviation of 0.53 which is a medium level. Quality of academic services came last with a mean of 3.06 and a standard deviation of 0.66. This indicates that the quality of educational services in Arab universities is Medium.

\section{Is there a significant impact at the level of $(\alpha \leq 0,05)$ of the perceived organizational support dimensions (organizational justice, leaders' behavior to support subordinates, participation in decision-making, and self-esteem of workers) on the quality of educational services at the Arab universities under study?}

To answer the third question, the multiple regression test was used to identify the impact of perceived organizational support dimensions (organizational justice, leaders' behavior to support subordinates, participation in decision-making, and self-esteem of workers) on the quality of educational services in the Arab universities under study.

Following the T- test values, it becomes clear that the sub-variables related to (organizational justice, leaders' behavior to support subordinates, self-esteem of workers, and participation in decision-making) have an impact on the quality of educational services at Arab universities, where the calculated $(t)$ values were $(2.178,2.284$, $3.824,2.864)$, respectively, are significant values at $(\alpha \leq 0,05)$.

This indicates that there is an impact of the perceived organizational support dimensions (organizational justice, leaders' behavior to support subordinates, self-esteem of workers, and participation in decision-making) on the quality of educational services as a whole. The effect size was $(71.3 \%)$. 


\section{Are there statistically significant differences at the level of $(\alpha \leq 0,05)$ in the quality of educational services level at Arab universities that can be attributed to demographic variables (gender, work nature and years of experience)?}

To answer the fourth question, the mean, standard deviations, and the Analysis of Covariance(ANCOVA)were used to identify the significance of the differences in the level of quality of educational services at Arab universities that can be attributed to demographic variables (gender, work nature and years of experience).The results are as follows:

The results of the variance test showed that there are significant differences at the level of $(\alpha \leq 0,05)$ in the quality of educational services level at Arab universities that can be attributed to the gender variable where the (F) value was 5.128, which is a significant value at the level of significance $(\alpha \leq 0,05)$. There were no significant differences at the level of $(\alpha \leq 0,05)$ in the quality of educational services level in Arab universities, that can be attributed to the variables of work nature of work and years of experience, where the (F) value was 0.567 and 0.700 , respectively, which are non-significant values at the level of $(\alpha \leq 0,05)$.

The result also shows there are significant differences at the level of $(\alpha \leq 0,05)$ in the quality of educational services level of (the quality of academic services, the quality of administrative services, the quality of facilities and equipment and the quality of reputation) at Arab universities that can be attributed to (gender), where (F) value was $(5.238,12.670,18.040,8.201,17.172)$, which are significant values at the level of $(\alpha \leq 0,05)$.To identify the source of the differences, an Independent Sample T-test was used, the results was as follows:

There are no significant differences at the level of $(\alpha \leq 0,05)$ in the quality of educational services level of (the quality of academic services, the quality of administrative services, the quality of facilities and equipment and the quality of reputation) at Arab universities that can be attributed to (experience and work nature), where (F) values for experience were $(0.007,0.278,0.059,0.838,0.234)$ which are non-significant values at the level of $(\alpha \leq 0,05)$.

The $(\mathrm{F})$ values for the work nature were $(1.172,0.729,0.149,1.207,0.084)$, respectively, are non-significant values at the level of $(\alpha \leq 0,05)$. The result also shows there are significant differences at the level of $(\alpha \leq 0,05)$. in the quality of educational services level at Arab universities due to the gender variable, where the (t)values were $(-2.159,-3.728,-4.378,-3.035,-4.243)$ respectively for the quality of ( academic services, administrative services, facilities and equipment, reputation and overall measurement) which are significant values at the level of $(\alpha \leq 0,05)$.or less. It was found that the source of the differences was in favor of females.

\section{Conclusions}

The main objective of this study is to explore the effect of perceived organizational support on the quality of educational services in Arab universities from the viewpoint of workers. According to the results of the study, there is a positive impact of perceived organizational support on the quality of educational services in Arab universities from the viewpoint of workers. Individuals expect equal benefits in value or values that they provide to others as defined by the theory of social exchange. The exchange of relationships is more positive between the university and the employees when the employees have the perceived organizational support, the confidence of the university, a high commitment, and a high proportion with the universities that will always lead them to display innovative work behavior.

The high compatibility of a person's skills, abilities, and personality with the requirements, cultures and values of the university helps in socializing better with his peers at the university through an enhanced level of positive work behavior. The behavior of the additional role towards the university, as well as stakeholders of the university, is not achieved unless the workers feel that the university supports and values their opinions, goals, considerations, motivations, values, and efforts that the university supports.

\section{References}

Abdel-Salam, Ramadan Mahmoud. (2005). The Impact of the Determinants of Perceived Organizational support on the Organizational Commitment Behavior of Employees. An applied Study on University Hospitals. Trade and Finance Journal, 2, Tanta University, Egypt.

Al-Adayleh, Oraib Abdel-Hamid. (2007). The Relationship Between Perceived Organizational Support and Organizational Loyalty at Jordanian universities, unpublished Master Thesis, Department of Foundations and Educational Administration, Mu'tah University, Jordan.

Al-Ani, AlaaAbd Al-Mawjoud. (2018). Compatibility between Perceived Organizational Support and Organizational Culture, Faculty of Management and Economics. University of Mosul. Iraq. 
Al-Enizi, Hajji; \& Al-Qarni, Saleh Ali. (2018). The Level of Perceived Organizational Support at Secondary Schools in Hafar Al-Batin Governorate and its Relationship to the Behavior of Organizational Citizenship of Male and Female Teachers, International Journal of Educational Studies.

Al-Hadabi, Daou. (2006). Predicting the quality of the educational service provided to university students in the context of the concepts of globalization. Journal of Social Studies, 21, University of Science and Technology. Sana'a.

Al-Haddad, S. Rand, A., \& Badran, S. (2018). The impact of the education services quality on students' satisfaction: an empirical study at the business schools in Jordan. Int. J. Business Excellence, 14(3), 393-314. https://doi.org/10.1504/IJBEX.2018.10010423

Al-Ka'abi, Hamid Salem. (2017). The Role of Perceived Support in Reducing Organizational Cynicism, Rafidain College, Iraq.

Allen DG, Shore LM, Griffeth RW. (2003). The role of perceived organizational support and supportive human resource practices in the turnover process. Journal of Management, 29(1), 99-118. https://doi.org/10.1016/S0149-2063(02)00222-2

Al-Rifa'i, Muhammad Hussein. (2009). Participatory Management and its Impact on Employees and Management, Unpublished PhD thesis, College of Management, Saint Clemance International University.

Al-Shanti, M., A. (2015). The Role of Organizational Support as a Modified Variable in the Relationship between Job Stress and Job Performance. Al-Quds Open University Journal for Administrative and Economic Research and Studies, 1(3).

Al-Tuwaijri, A., \& Abdullah, F. (2016). The Quality Level of Educational Services at Saudi Universities in the Light of a developedScale, the Arab Journal for Quality Assurance of University Education, 25.

Blau, P.M. (1964). Exchange and power in social life. New York: Wiley.

Dawley, D. D., Andrews, M. C., \& Bucklew, N. S. (2008). Mentoring, supervisor support, and perceived organizational support: what matters most? Leadership \& Organization Development Journal, 29(3), 235-247. https://doi.org/10.1108/01437730810861290

Douglas, J., Douglas, A., \& Barnes, B. (2006). Measuring student satisfaction at a UK university. Quality assurance in education, 14(3), 251-267. https://doi.org/10.1108/09684880610678568

Eisenberger R, Cummings J, Armeli S, Lynch P. (1997). Perceived organizational support, discretionary treatment, and job satisfaction. Journal of Applied Psychology, 82(5): 812-820. https://doi.org/10.1037/0021-9010.82.5.812

Issa, A., \& Siddiek, A. (2012). Higher Education in the Arab World \& Challenges of Labor Market, International Journal of Business and Social Science, 3(9), 146-151.

Jayasree, K. \& Sheela, M.V. (2012). Perceived Organizational Support - An Overview of its Antecedents and Consequences. International Journal of Multidisciplinary Research. 2(4), 1-12. https://doi.org/10.1016/j.sbspro.2012.09.173

Sady, M., Zak, A., \& Rzepka, K. (2019). The Role of Universities in Sustainability-Oriented Competencies Development: Insights from an Empirical Study on Polish Universities, Adm. Sci., 9(62). 1-20. https://doi.org/10.3390/admsci9030062

Shahly, N. (2016). Organizational Support and its Relationship to Job Stability. Unpublished Master Thesis, University of Mohamed Boudiaf - Al-Messila, Algeria.

Zaqai, H., \& Wazzani, M. (2017). Quality Level of Educational Services and their Impact on Student Satisfaction, The Arab Journal of Quality Assurance of University Education, 10(30).

\section{Copyrights}

Copyright for this article is retained by the author(s), with first publication rights granted to the journal.

This is an open-access article distributed under the terms and conditions of the Creative Commons Attribution license (http://creativecommons.org/licenses/by/3.0/). 